\title{
Retraction notice for: "Comparison of Arndt- endobronchial blocker plus laryngeal mask airway with left-sided double-lumen endobronchial tube in one-lung ventilation in thoracic surgery in the morbidly obese" [Braz J Med Biol Res (2018) 51(2): e6825]
}

Z.J. Zhang, M.L. Zheng, Y. Nie and Z.Q. Niu

Department of Anesthesiology, the Cangzhou Central Hospital, Cangzhou, Hebei, China

Retraction for: Braz J Med Biol Res | doi: 10.1590/1414-431X20176825 | PMID: 29267506

The Brazilian Journal of Medical and Biological Research was contacted by one specialist questioning the validity of this study. [Click here to view Specialist message]

The authors were contacted on May 7 and 22, 2018 to answer the questions one-by-one. As of June 29, 2018, we did not receive an answer from the authors.

The Editors decided to Retract the article: “Comparison of Arndt-endobronchial blocker plus laryngeal mask airway with left-sided double-lumen endobronchial tube in one-lung ventilation in thoracic surgery in the morbidly obese" that was published in volume 51 no. 2 (2018) (Epub Dec 18, 2017) in the Brazilian Journal of Medical and Biological Research < http://dx.doi.org/10.1590/1414-431X20176825> PMID: 29267506.

The Brazilian Journal of Medical and Biological Research informed all authors before the publication of this Retraction. 


\title{
Comparison of Arndt-endobronchial blocker plus laryngeal mask airway with left-sided double-ly han endobronchial tube in one-lung ventilation in thor, ci, surgery in the morbidly obse
}

\author{
Z.J. Zhang, M.L. Zher ฯ V Vie = d Z.Q. Niu \\ Department of Anesthesiology, the Cangzhou Centre' rospital, ngzhou, Hebei, China
}

\begin{abstract}
This study aimed to evaluate the feasibility and performance of Arndt-endobron mask airway (LMA) compared with left-sided double-lumen endobronchial tube (L-D. in morbidly obese patients in one-lung ventilation (OLV). In a prospective, randomized double-blind controlled clir il 80 ibidly obese patients (ASA I-III, aged 20-70) undergoing general anesthesia for elective thoracic surgeries wer anc allocated into groups Arndt ( $n=40)$ and L-DLT $(n=40)$. In group Arndt, a LMA ${ }^{\mathrm{TM}}$ Proseal was placed followed by an Arn ndobronchial blocker. In group L-DLT, patients were intubated with a left-sided double-lumen endotracheal tube. Primary en oints were the airway establishment, ease of insertion, oxygenation, lung collapse and surgical field exposy sults showed similar ease of airway establishment and tube/device insertion between the two groups. Oxygen arteriz oressu. ${ }^{\prime} \mathrm{PaO}_{2}$ ) of patients in the Arndt group was significantly higher than L-DLT $(154 \pm 46$ vs $105 \pm 52 \mathrm{mmHg} ; \mathrm{P}<0.05)$. lity of $\mathrm{ig}$ collapse and surgical field exposure in the Arndt group was significantly better than L-DLT (effective ra' $100 \quad \mathrm{~N} 0^{\circ} \quad \mathrm{P}<0.05$ ). Duration of surgery and anesthesia were significantly shorter in the Arndt group (2.4 \pm 1.7 vs $3 \leq 1.8$ and $2 . \pm 1.9$ vs $3.8 \pm 1.8 \mathrm{~h}$, respectively; $\mathrm{P}<0.05)$. Incidence of hoarseness of voice and incidence and severity of th surgery were significantly lower in the Arndt grol $(\mathrm{P}<\mathrm{\tau}-\mathrm{r}$, dings suggested that Arndt-endobronchial blocker combined with LMA can serve as a promising alternative norbidly sese patients in OLV in thoracic surgery.
\end{abstract}

Key words: Laryngeal mask airway; Arnd' Jobronch 'Jlocker; L-DLT; One-lung ventilation; Thoracic surgery; Morbidly obese

\section{Introduction}

Management of one-lung cilation (ULV) continues to be a challenge in clinical pi tict A double-lumen endobronchial tube (DLT) or $a b$, hial blocker is usually used to achieve one-ly on tilat (OLV) in thoracic surgeries (2). However $\mathrm{T}$ is ans for nasal intubation in some cases due 'o arge outer diameter and distal curvature (3), r cularly natients with difficult airways (Mallampati f a ia 3 or 4), restricted mouth opening and limiter' reck exu ion, as it is bulkier and more rigid than a $s^{\prime}$ gle-1 men $^{\prime}$ endotracheal tube $(4,5)$. Distortion of the tra $\mathrm{O}^{\mathrm{r}}$ unchin tree would cause difficulties in placement of a T.f Arndt bronchial blocker might be better i. suc cast

C natients are known to have increased risk of c slications in airway management due to altered airway atomy. Short neck, limited neck extension and fat deposition in the pharyngeal wall are some of the causative factors (6). Obese patients are also likely to have obstructive sleep apnea (7-9). Maintenance of airway for surgical procedures is difficult due to changing in pulmonary mechanics and circulation $(10,11)$. Increased residual gastric volumes and gastric fluid acidity increase the need for aspirations. Intubation with a DLT might be difficult due to its larger size and shape. At present, although techniques for lung isolation in thoracic surgery are increasing (12), reports on its optimal use in morbidly obese patients are still relatively scarce. A recent study by Campos et al. (13) on comparison between the use of L-DLT and Arndt blocker in lung isolation in the morbidly obese found that both techniques are clinically equivalent in terms of intubation difficulty and time for lung collapse.

Laryngeal mask airway (LMA) is a relatively new device. It is less invasive and causes less airway resistance. However, its application is still limited in OLV (14). In the 
present study, we compared the outcome of the combination of Arndt-endobronchial blocker and LMA with L-DLT in the morbidly obese patients in OLV in thoracic surgery. This was done by evaluating the airway establishment, ease of insertion, oxygenation, lung collapse, incidence of voice hoarseness and incidence and severity of throat pain of the patients.

We hypothesized that endotracheal intubation of the morbidly obese patients with Arndt-endobronchial blocker combined with LMA would be more feasible and yield better performance than L-DLT in OLV in elective thoracic surgery.

\section{Material and Methods}

\section{Selection of patients}

The protocol for clinical investigation performed in this study was approved by the Ethics Committee of the Cangzhou Central Hospital, Cangzhou, Hebei (No. 2015063). Written informed consent was obtained from all participants. Eighty adult morbidly obese patients with a $\mathrm{BMI}>35 \mathrm{~kg} / \mathrm{m}^{2}$ (age, 20-70 years; American Society of Anesthesiologists physical status I-III) who were scheduled for elective thoracic surgery from September 2015 to December 2016 were randomly assigned into 2 groups Arndt group (Arndt-endobronchial blocker combined with LMA) and L-DLT group, with 40 patients in each $c$ up (Figure 1).

Sequence generation was achieved with a ized random number generator. Allocation cr cealm was achieved by using sealed opaque nes. Alr aspects of anesthetic management, including pla $\checkmark$ the

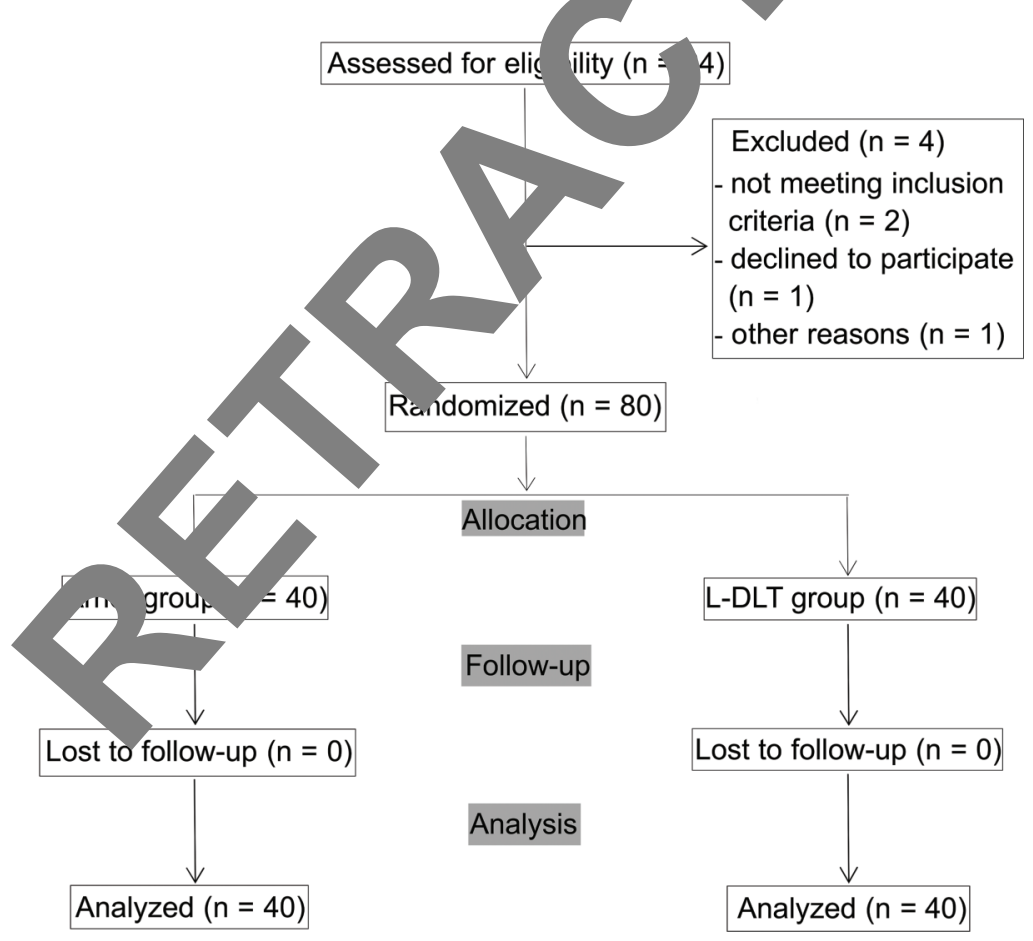

tubes/devices, were taken care of by two experience anesthetists. All patients were informed before a procedure and were blinded to group allocation.

Exclusion criteria included an age of 0 ears preoperative hoarseness, mouth opening of $<5$, symptomatic or untreated gastroesophrqeal reflux, agnancy, surgery within $>6 \mathrm{~h}$.

\section{Methods of anesthesia}

All patients were premedi ted wi $0.01 \mathrm{mg} / \mathrm{kg}$ intramuscular (im) injection ont hydrochloride and $0.04 \mathrm{mg} / \mathrm{kg}$ of mide slarm $\mathrm{min}$ before induction of anesthesia. After al in th operation room, an intravenous (iv) can da placed and patients were maintained with i-cion of ger's solution at a rate of $5 \mathrm{~mL} \cdot \mathrm{kg}^{-1}$. Ir uction of general anesthesia was achieved with 5 tanyl, $1.5-2 \mathrm{mg} / \mathrm{kg}$ propofol, and $0.1-0.15 \mathrm{~ms}$ vecuronium. Central venous pressure of aht inte al jugular vein was measured and routine $m$ itor theart rate $(H R)$, respiratory rate $(R R)$, electrocarc aphy, oxygen arterial pressure $\left(\mathrm{SpO}_{2}\right)$, oral temperature adial artery pressure, and urine output were rmed continuously.

A $r$ the patients were in full oxygen supply and comp e muscle relaxation, a LMA ${ }^{\mathrm{TM}}$ Proseal (size 4 for and size 5 for male; LMA North America, Inc., US. -) was placed followed by a $9 \mathrm{Fr}$ Arndt endobronchial rocker (Cook ${ }^{\mathrm{R}}$ Critical Care, USA) for those in the Arndt group. Patients in the L-DLT group were intubated with a left-sided [37-41] Fr double-lumen endobronchial tube (L-DLT; Broncho-cath ${ }^{\mathrm{TM}}$, Mallinckrodt Laboratories, Ireland).

Figure 1. CONSORT flow diagram. Arndt: Arndtendobronchial blocker association; L-DLT: leftsided double-lumen endobronchial tube. 
Tube sizes were determined by measurement of the width of the tracheal diameter (in $\mathrm{mm}$ ) from the preoperative chest radiographs (15). When the Arndt blocker was in optimal position, the wire loop was removed and the wire channel was used for suction. The cuff pressure was maintained between 55 and $60 \mathrm{cmH}_{2} \mathrm{O}$ with a manometer (Mallinckrodt, Germany). All patients were given 1-2 $\mu \mathrm{g}$. $\mathrm{kg}^{-1} \cdot \mathrm{min}^{-1}$ of vecuronium with intermittent intravenous injection of fentanyl and inhalation anesthesia of 1-2\% isoflurane. Epidural lines were placed in all patients.

\section{Maintaining of patients}

Accuracy of the Arndt or L-DLT was assessed by using a flexible fiberoptic bronchoscopy (FOB; BF type 3 C40; Olympus, Japan). Placements were confirmed by two experience thoracic anesthesiologists and were again checked after lateral positioning. Patients were carefully positioned for operation. The head was fixed and after turning to the lateral decubitus position, OLV was initiated.

During two-lung ventilation (TLV), patients were maintained at tidal volume $(\mathrm{Vt})$ of $8 \mathrm{~mL} / \mathrm{kg}$, inspiratory/expiratory ratio (I:E) of $1: 1.5$, fraction of inspired oxygen $\left(\mathrm{F}_{\mathrm{I}} \mathrm{O}_{2}\right)$ of 0.6 and RR of 12 breaths per min. During OLV, patients were maintained at $\mathrm{Vt}$ of $6 \mathrm{~mL} / \mathrm{kg}, \mathrm{I}: \mathrm{E}$ of $1: 2, \mathrm{~F}_{1} \mathrm{O}_{2}$ of 0.6 and respiratory rate of 15 breaths per min. In order to prevent ventilation/perfusion ratio imbalance due to rolong OLV, suction was performed intermittently. ceri blood gases were measured. Open thoracotomy or assisted thoracoscopic surgery (VATS) was erform Tube/device position and adequacy of lung $0_{n}$. se were evaluated each 30 min during surgery.

After surgery, all patients were car ..., extubate $\mathrm{and}$ received supplementary oxygen at 5 min via facemask for $30 \mathrm{~min}$. This was continued if $\mathrm{SpO}_{2}$ as les than $95 \%$ whilst breathing room air. For mostopera. din therapy, sufentanil and $0.25 \%$ bupivaca riven upon request via the epidural catheter. Par, $\vartheta^{+}$10 and piritramide, $0.05 \mathrm{mg} / \mathrm{kg}$ intravenous re gi when analgesia was inappropriate.

\section{Observation an data "ection}

Intubation was re rded with a stopwatch from the time wher the $t$ s or devices passed the vocal cords until the ?sthesiolog. is confirmed its correct placement

Table 1 sess endo-tracheal tube malpositions. and optimal position with FOB aid. A maximum of three placement attempts was allowed. Each attempt war efined as withdrawing the bronchial lumen of the Arn or $L$ OLT into the trachea and then attempting to repos.

Correction of any inadequate seal of the LMA formed. In case of inability to intubate with a DLT, a s lumen tube and exchange catheter (Cou Critic Care) was used to place a DLT, and the wa d $d$ to the original attempt time. Criteria us to assess malposition are as shown in Table 1.

Arterial blood gases, $\mathrm{PaC}_{2} \mathrm{PaC}$ on ntrinsic positive end-expiratory pressure ere "lected during two-lung ventilation (baseline $d ?$ and 30 , a after OLV.

After the pleura has ned and the lung could be seen, the quality $c^{\prime} \mathrm{g}$ collap was evaluated. The time for lung isolatic colls se was measured from the institution of one-lur Evaluation of $\mathrm{su}$. cal exposure (evaluation criteria as referred ampos il. (16) method) were performed by two thor 'cs as independently who were blind to the group a ynment. Collapse of the lung was assessed as follows: spontaneous, 2) assisted with suction, or anual. The conditions of surgery were ranked as exce. th, fair, or poor: 1) excellent: complete collapse with nerfec surgical exposure, 2) fair: total collapse, but the ill had residual air, and 3) poor: no collapse was acl.eved or partial collapse with interference in surgical xposure. At the end of surgery, the surgeons gave the overall assessment of the lung isolation. Results were recorded and the average was calculated.

An investigator blind to the group assignment of the patients asked the patients specific questions regarding postoperative hoarseness and throat pain at the postanesthesia care unit (PACU) and 12, 24, 48, 72, and $>72 \mathrm{~h}$ after surgery. Throat pain score assessment was performed with a numerical rating scale (NRS) ranging from 1 to 10 recorded by direct questioning of the patients. NRS $=0$ and NRS $>0$ were considered as painless and painful throat, respectively. All patients were trained on how to answer the NRS.

\section{Statistical analysis}

Primary endpoints were the number of times the tube/ devices were successfully position at the first intubation

Table 1. Aa to sess endo-tracheal tube malpositions.
- Brndt blocker or DLT in the non-targeted bronchus
carina

DLT: double-lumen endobronchial tube 
Table 2. Demographic characteristics, preoperative pulmonary functions and preoperative arterial blood gas values of the patients in the Arndt and L-DLT groups.

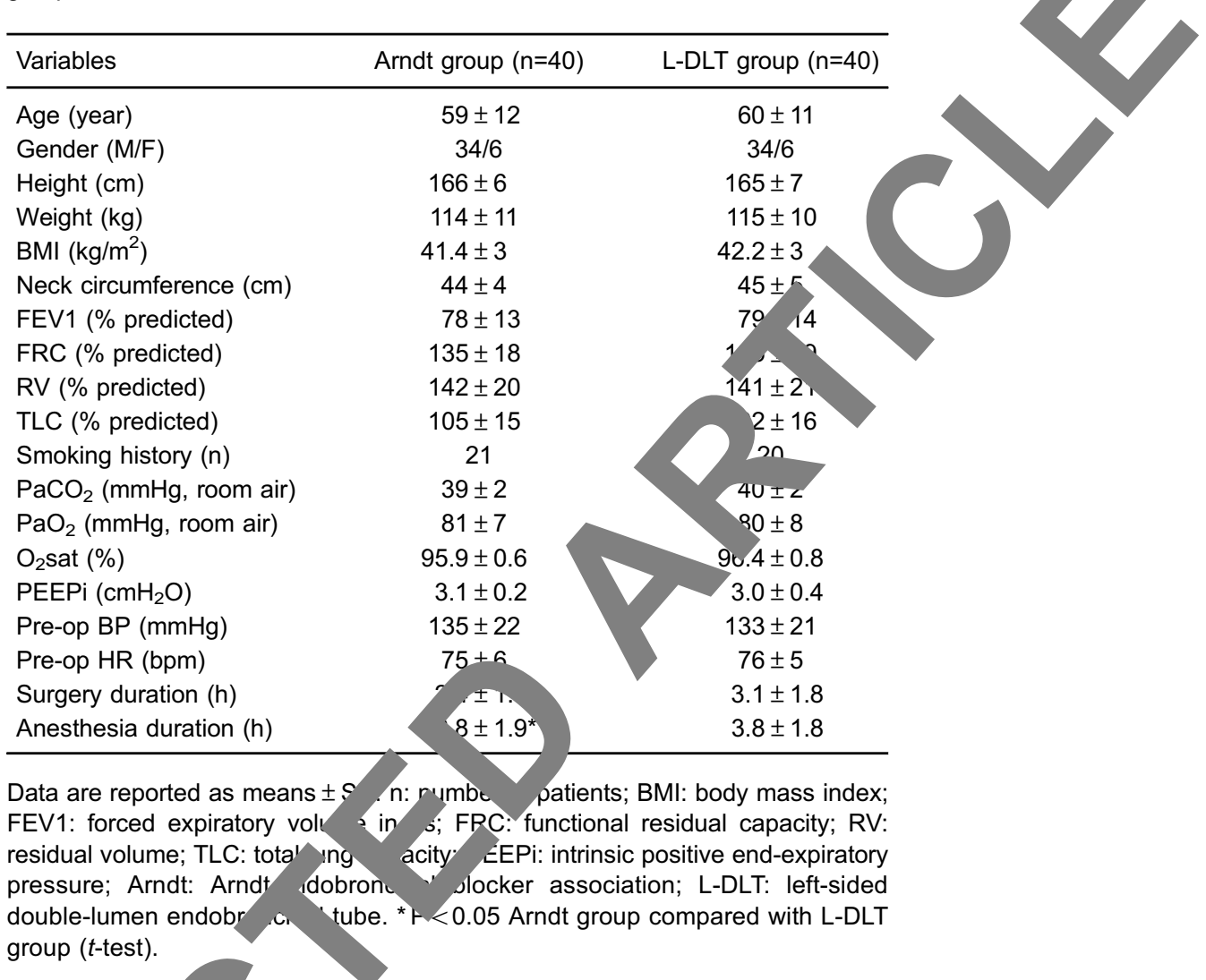

attempt, the number of malposition the tin required to achieve optimal position vorified $b$, oxygenation, quality of lung collapse c a field exposure; Secondary outcome were inc of hoarseness of voice and incidence an verity throat pain.

The total number pa nts ruited was based on research of previous 8 ), to allow detection of at least 2 min di reno setween the two groups in the time of tube $c$ vice pla ment, with an $\alpha$ of 0.05 and power of 0.80 .

Data reported a neans $\pm S D$. Comparison between the tw gro's was performed using Student's $t$-test. $\mathrm{P}<0.0$ s $\mathrm{co}$ idered to be statistically significant. Ar is $w r$, formed using SPSS statistical software ersi 19.0, sPSS Inc., USA).

\section{R. vits}

No patient dropped out of the study. In the Arndt group, sizes of the single-lumen tracheal tubes for the Arndt ${ }^{\mathbb{R}}$ blocker 9 Fr were $8.0 \mathrm{~mm}$ ID $(n=6), 8.5 \mathrm{~mm}$ ID $(n=22)$, and $9.0 \mathrm{~mm}$ ID $(\mathrm{n}=12)$. In the L-DLT group, the tube sizes used were $37 \operatorname{Fr}(n=19), 39 \operatorname{Fr}(n=13)$, and $41 \operatorname{Fr}(n=8)$.

\section{Demographic characteristics}

Patients in the Arndt group and L-DLT group were equivalent in their basic characteristics with regard to age, male/female ratio, height, weight, BMI, neck circumference (NC), pre-operative spirometry results and pre-operative hemodynamic parameters (Table 2).

\section{Duration of surgery and anesthesia}

The duration of surgery and anesthesia for the Arndt group was statistically shorter than the L-DLT group (2.4 \pm 1.7 vs $3.1 \pm 1.8$ and $2.8 \pm 1.9$ vs $3.8 \pm 1.8 \mathrm{~h}$, respectively; $\mathrm{P}<0.05$; Table 2).

Surgical procedures performed in the Arndt and L-DLT group are shown in Table 3. The number of thoracotomies and VATS in the two groups were not significantly different $(P=0.48)$, nor were the numbers of left- and right-sided surgeries $(P=0.36)$.

\section{Number of intubation attempts}

The number of intubation attempts and other airway parameters for group Arndt and L-DLT are reported in Table 3. Parameters between the two groups were not significantly different. 
Table 3. Type of thoracic surgery and related outcomes of the 80 patients and airway parameters.

\begin{tabular}{|c|c|c|c|}
\hline Type of procedure & Arndt group (n-40) & L-DLT group $(n=40)$ & $P$ value \\
\hline \multicolumn{3}{|l|}{ Lobectomy } & 0.36 \\
\hline Right-sided & 16 & 14 & \\
\hline Left-sided & 8 & 10 & \\
\hline \multicolumn{4}{|l|}{ Pneumonectomy } \\
\hline Right-sided & 1 & 0 & \\
\hline Left-sided & 1 & 2 & \\
\hline Upper and middle esophageal resection & 14 & 14 & \\
\hline \multicolumn{4}{|l|}{ Airway parameters } \\
\hline Mallampati grade & $2.1 \pm 1.1$ & & 0.78 \\
\hline Cormack grade & $2.2 \pm 1.3$ & & 0.68 \\
\hline Intubation attempts $(\mathrm{n})$ & $1.1 \pm 0.1$ & & 0.56 \\
\hline First attempt $(n)$ & 37 & 36 & \\
\hline Second attempt (n) & 3 & & \\
\hline Third attempt $(n)$ & 0 & 1 & \\
\hline Intubation duration (min) & $3.3 \pm 0.4$ & \pm 0.5 & 0.84 \\
\hline Positioning attempts $(\mathrm{n})$ & $1.1 \pm 0.1$ & \pm 0.1 & 0.81 \\
\hline Number of malpositions (n) & 3 & 3 & \\
\hline Positioning duration (min) & $4.4 \pm 0.6$ & $3.2 \pm 0.4$ & 0.92 \\
\hline Adjustments (n) & $0-2$ & $0.4 \pm 0.1$ & 0.35 \\
\hline
\end{tabular}

In the Arndt group, the size of LMA ${ }^{\mathrm{TM}}$ Proseal $4 \mathrm{~S}$ adequate with minimal secretions and without ther $c_{c}$ plications. There was no dislodgement of a airway obstruction or pulmonary aspiration during anest.

In the L-DLT group, for cases th culed to acreve successful tube intubation in the first tempt, second or third attempt was performed. A single men tr heal tube followed by insertion of an 11 Fr Cook exchange catheter was used to advance without difficulties.

\section{Malpositions}

There were 3 mal sitic s rep ed in the Arndt group and 3 in the L-DLT g. $30 \mathrm{~min}$. This occurred when turning the atien, from supine to the lateral position. For the? ients of Arndt group, the tip of the blocker was cusloas above the tracheal carina, while for the 3 pat' its of the $L / L T$ group, the endobronchial cuff was he rate above the tracheal carina. All cases were repositı with $\mathrm{OB}$ aid with no further complications. Tr era sency of malpositions between the two oup was nu significantly different (Table 3).

\section{Ga xchange data during OLV}

Du.ng OLV, $\mathrm{PaO}_{2}$ of the patients in the Arndt group (154 $\pm 46 \mathrm{mmHg}$ ) was significantly higher than the L-DLT group $(105 \pm 52 \mathrm{mmHg} ; \mathrm{P}<0.05)$ while $\mathrm{P}(\mathrm{A}-\mathrm{a}) \mathrm{O}_{2}$ of the patients in the Arndt group $(194 \pm 42 \mathrm{mmHg})$ was significantly lower than the L-DLT group $(243 \pm 45 \mathrm{mmHg}$; $\mathrm{P}<0.05$; Table 4).

\section{ang collapse and surgical field exposure}

The time required for lung collapse was $14.8 \pm 6.2 \mathrm{~min}$ for the Arndt group and 17.0 $\pm 6.4 \mathrm{~min}$ for the L-DLT group $(P=0.39)$. Quality of lung collapse and surgical field exposure for the Arndt group was significantly better than the L-DLT group (excellent $n=40$, fair $n=0$, poor $n=0$ for Arndt group; excellent $n=36$, fair $n=0$, poor $n=4$ for $L-D L T$ group; effective rate 100 vs $90 \% ; \mathrm{P}<0.05)$.

\section{Incidence of hoarseness of voice, incidence of throat pain and throat pain score}

The incidence of hoarseness of voice and throat pain, and the mean score for throat pain among the patients in the Arndt group at PACU and 12, 24, 48, $72 \mathrm{~h}$ after thoracic surgery were significantly lower than the L-DLT group ( $P<0.05$; Table 5). No incidence of hoarseness of voice and throat pain occurred after $72 \mathrm{~h}$ of surgery.

\section{Discussion}

Obesity is a worldwide health problem and the prevalence of morbid obesity is increasing over time. Thus, more patients requiring anesthesia for thoracic surgery will be overweight or obese. Obese patients are at risk for difficulties placing a DLT. For majority of cases, a left-sided DLT is preferred over a right-sided DLT due to its greater margin of safety. Increase in the NC could serves as a leading risk factor for difficult intubation $(19,20)$, and it is neither associated with increased BMI or absolute obesity (20). 
Table 4. Gas exchange data of the 80 patients during OLV.

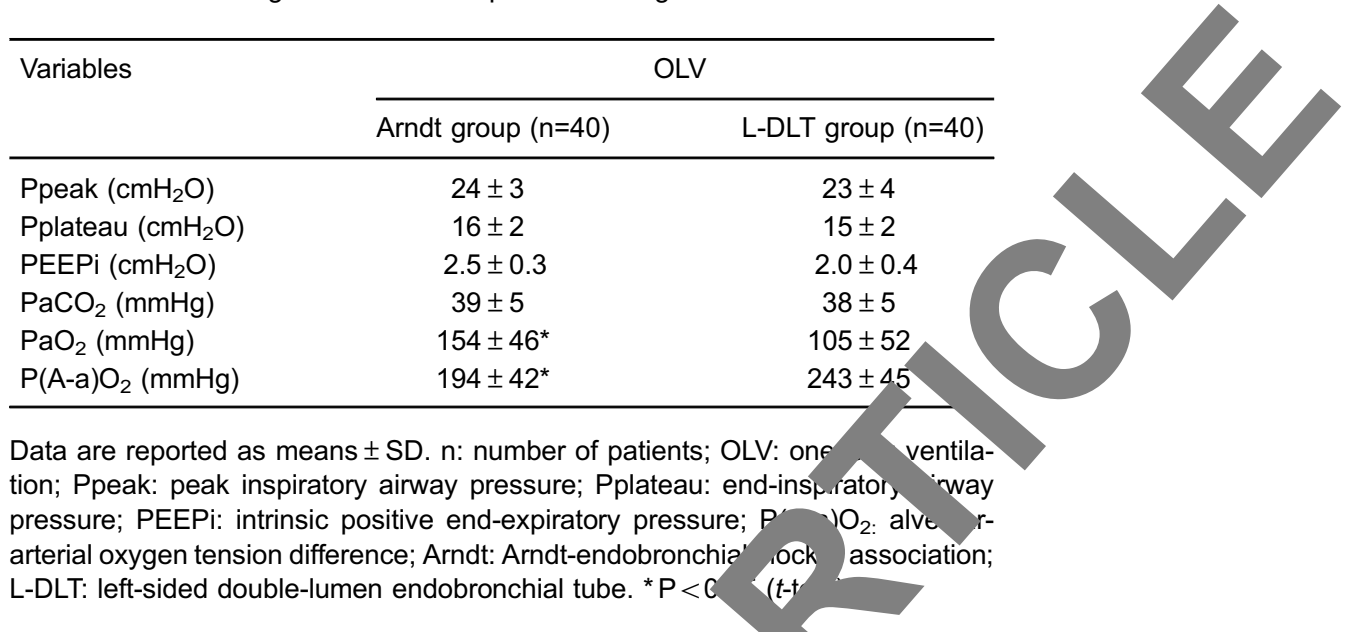

Table 5. Incidence of hoarseness of voice, incidence of throat pain and throat at athe 80 patients at PACU and 12, 24, 48,72 , and $>72 \mathrm{~h}$ after thoracic surgery.

\begin{tabular}{|c|c|c|c|c|c|c|c|}
\hline & \multicolumn{2}{|c|}{ Hoarseness of voice } & \multicolumn{2}{|c|}{ Throat pain } & n score by $r$ & cal ratin & e (NRS) \\
\hline & \multirow{2}{*}{$\begin{array}{l}\text { Arndt } \\
(n, \%)\end{array}$} & \multirow{2}{*}{$\begin{array}{l}\text { L-DLT } \\
(n, \%)\end{array}$} & \multirow{2}{*}{$\begin{array}{l}\text { Arndt } \\
(\mathrm{n}, \%)\end{array}$} & \multicolumn{2}{|c|}{ Arndt group } & \multicolumn{2}{|c|}{ L-DLT group } \\
\hline & & & & a & Maximum & Mean & Maximum \\
\hline PACU & $3(7.5 \%)^{*}$ & $9(22.5 \%)$ & $6(15 \%)^{*}$ & $2^{*}$ & 3 & 5 & 6 \\
\hline $12 \mathrm{~h}$ & $4(10 \%)^{*}$ & $12(30 \%)$ & $8(20 \%)^{*}$ & $3^{*}$ & 4 & 7 & 8 \\
\hline $24 \mathrm{~h}$ & $3(7.5 \%)^{\star}$ & $10(25 \%)$ & $7(17.5 \%$ & $2^{*}$ & 3 & 5 & 7 \\
\hline $48 \mathrm{~h}$ & $2(5 \%)^{*}$ & 7 (17.5\%) & $5(12.5$ & $1^{*}$ & 2 & 3 & 5 \\
\hline $72 \mathrm{~h}$ & $1(2.5 \%)^{*}$ & $4(10 \%)$ & $1(2.5 \%)^{*}$ & $0.25^{*}$ & 1 & 2 & 3 \\
\hline$>72 \mathrm{~h}$ & $0(0 \%)$ & $0(0 \%)$ & $C \rightarrow$ & 0 & 0 & 0 & 0 \\
\hline
\end{tabular}

Studies found similar diffic v Irrabation for both Arndt and DLT, howeve $\mathrm{T}$ pl ements were exposed to additional risk suct $s \mathrm{p}$ ential $\mathrm{r}$ aspiration, progressive desaturation du ange and direct damage leading to trach al or nnchial perforation or tension pneumothoray 1). LM - , could be a primary option in case of difficult an viled airways. However, LMA alone is not $a b^{\prime}$ to provide LV in thoracic surgeries. Studies showe nat mbination of LMA with Arndt-endobronchial blocker a pro de effective surgical exposure in OLV. Tr hnic as also associated with reduced fluctuaons hemodynamic response (14). LMA causes less " r runce than endotracheal intubation which may, in lead to decreased bronchoconstrictive reflex, fewer pulmo ary infections and less atelectasis (22).

Obesity is associated with restrictive lung disease due to increased intraabdominal pressure and decreased chest wall compliance $(23,24)$. A study showed that decreases in forced expiratory volume in $1 \mathrm{~s}$ and forced vital capacity are inversely proportional to the increase in BMI (25).
Low functional residual capacity and expiratory reserve volume contribute, respectively, to hypoventilation and poor lung collapse in OLV (26). Decrease in lung and chest wall compliance may also result in intraoperative hypoventilation during mechanical ventilation and increased work for breathing in the postoperative period when patients resume spontaneous ventilation (26).

In the present study, we compared the ease and success of placement of tube/devices in the morbidly obese patients in OLV for thoracic surgery between the Arndt and L-DLT group. In the Arndt group, selection of an appropriate LMA size is important. First, the mask should be able to provide an airtight seal during positive pressure ventilation. Second, the mask should not produce excessive pressure to the pharynx. Lastly, the mask should not be too large (27). In a study done by Voyagis et al. (28) attempting to decide whether the patient's age or weight was a better indicator for selecting the appropriate size of a laryngeal mask, it was found that the mean peak inspiratory pressure at which air leak occurred was greater 
using the sex-related method compared to the weightrelated method. In a study by Asai et al. (27), it was found that a larger size (size 4 in females and size 5 in males) provided an airtight seal more frequently than smaller sizes, without producing a higher pressure on the pharynx. The incidence of air leak was significantly lower when a larger mask was used. Kagawa and Obara (29) proposed a formula for LMA size based on patient weight relationship.

In our study, the size of LMA used (size 4 in females and size 5 in males) was adequate to provide a proper seal for the patients. With the combination of Arndt blocker and LMA, tracheal suctioning can be performed via the internal channel of the FOB via direct visualization (14). There was seldom requirement for suctioning in patients of the Arndt group. It has been reported in a previous study that the oropharyngeal leak pressure of the LMA ProSeal was $32 \mathrm{cmH}_{2} \mathrm{O}$ (range, 12-40 $\mathrm{cmH}_{2} \mathrm{O}$ ) $(14,30$ ). In the present study, the peak airway pressure during OLV was $24 \pm 3 \mathrm{cmH}_{2} \mathrm{O}$ in the Arndt group, which is far below the leak pressure of the LMA ProSeal and this is comparable with the previous study (14).

In the Arndt group, a second attempt was necessary to achieve successful intubation in 3 patients. Securinc the airway with a single-lumen tracheal tube is the most important step in patients with difficult airways nis may have an advantage as it avoids the use of tub exchanger (13).

In the L-DLT group, two or three attr upts w necessary to achieve successful intubation Intubation with a single-lumen tracheal tube wed by an airway exchange catheter is $r$ easier than a standard laryngoscope with a DLT $c$ e to the arger size and shape of a DLT (31). Beside Dhon ur et al. (32) described using a CTrarh LMA olaternative approach for morbidly obese

A study by Gonzalez et al. 3? iound NC $>43 \mathrm{~cm}$ as an indicator for inc a $r$ of difficult intubation while Neligan et al. (4) fo nd no predictive association between NC and a. Another study by Riad et al. (35) sund $\mathrm{Ml}>50$ and $\mathrm{NC}>42 \mathrm{~cm}$ as the independ vredicto for difficult intubation and $\mathrm{BMI}>50$ ano malc onder as independent predictors for difficult $m$ sk ventilatio. In our study, the mean NC of the patient in th Arndt group and L-DLT group was $44 \pm 4$ and 45 smectively, while the mean BMl was 413 ar $- \pm 3 \mathrm{~kg}$, respectively. In the Arndt group, e $\mathrm{N}$ of the patients who failed the first intubation 4. 45.5, 45.8, and $46.2 \mathrm{~cm}$, while the BMI wa $3.2,43.7$, and $44.1 \mathrm{~kg}$, respectively, which was not signitı, antly different from the other patients in the same group. In the L-DLT group, the NC of the patients who failed first intubation attempt was $45.8,46.3$, and $47.0 \mathrm{~cm}$, while the BMI was $43.6,43.9$, and $44.3 \mathrm{~kg}$, respectively, which was also not significantly different from the other patients in the L-DLT group.
Overall, in our study, difficult intubation was not significantly different between the groups. The findir $>$ were comparable with the previous study done for $c$ npa' son between Arndt and DLT in obese (13) and no ol eight (14) patients, and either with (14) or without bination with LMA.

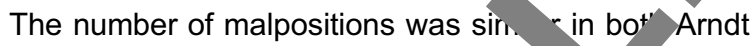
and L-DLT groups. Malpositionip ight due to obese patients having shorter recks and recreased neck mobility than normal. With hese $p$ ents, it might be difficult to support the position with a flex-pos $\mathrm{on}$ Patlents in the Arndt group required laryngr mask $m_{1}$ pulation resulting in the increase in the pos, ning duration by $1.2 \mathrm{~min}$. However, the in se was ot significantly different from the L-DLT, rou

$\mathrm{PaO}_{2}$ of $\mathrm{p}$ Arndt group was significantly higher than the $\checkmark L T$ during OLV. The time for lung collapse cimilar both groups, and was comparable with the vic done by Campos et al. (13) and Li et al. (1 Quality of lung collapse and surgical field exposure in e Arndt group was significantly better than -DLT group, which probably contributed to the shorter dura of surgery and anesthesia for the Arndt group.

$\mathrm{Br}$ chial blockers have been considered the best for patients with difficult airways. There is no need to $u$ place a tube if mechanical ventilation is required (36). isk of airway complications may increase when using a DLT compared to a bronchial blocker for achieving OLV (37). Sore throat and hoarseness of voice are among the well-known postoperative complications after tracheal intubation (38).

In the present study, the incidence of hoarseness of voice and the incidence and severity of throat pain in the Arndt group in the PACU and 12, 24, 48, and $72 \mathrm{~h}$ after thoracic surgery were significantly lower than the L-DLT group $(P<0.05)$, which were consistent with previous studies $(14,37)$. Curved endobronchial lumen and size of the L-DLT tubes could be the main risk factors for postoperative hoarseness during intubation and extubation. There was no incidence of hoarseness of voice and throat pain after $72 \mathrm{~h}$ of surgery.

LMA may cause laryngopharyngeal mucosal injury in a time-dependent manner. Studies found that prolonged use of LMA in pigs for $<9 \mathrm{~h}$ was associated with no or mild changes in the laryngopharyngeal mucosa while clear signs of mucosal injury were observed after $\geqslant 12 \mathrm{~h}$ use (39). A previous study reported that injury scores of the bronchus and vocal cords in the DLT group were significantly higher than Arndt combined with ProSeal ${ }^{\mathrm{TM}}$, while the larynx injury score was significantly lower in the DLT group (14). In the present study, surgeries of $>6 \mathrm{~h}$ duration were excluded to minimize risk.

The use of an Arndt endobronchial blocker may overcome some of the limitations of DLT, such as difficult airway. When applied in combination with Proseal ${ }^{\mathrm{TM}}$ LMA, 
the limitations of the traditional use of endobronchial blockers can be further overcome. This novel combination can be very useful in many clinical scenarios, and make thoracic anesthesia much easier (40). Combination of Arndt with LMA may exhibit more advantages over DLTs particularly in less invasive day-case thoracic surgeries, the number of which is rapidly increasing throughout the world (14). Development of newer designs of LMA would help to improve its usage and provide optimal and better benefits in the future.

In conclusion, combination of the Arndt-endobronchial blocker with LMA can be a promising alternative for

\section{References}

1. Ferreira HC, Zin WA, Rocco PRM. Physiopathology and clinical management of one-lung ventilation. J Bras Pneumol 2004; 30: 566-573, doi: 10.1590/S1806-37132004000600012.

2. Brodsky JB. Lung separation and the difficult airway. $\mathrm{Br} J$ Anaesth 2009; 103 (Suppl 1): i66-i75, doi: 10.1093/bja/ aep262.

3. Angie Ho CY, Chen CY, Yang MW, Liu HP. Use of the Arndt wire-guided endobronchial blocker via nasal for one-lung ventilation in patient with anticipated restricted mouth opening for esophagectomy. Eur J Cardiothorac Surg 2005; 28: 174 175, doi: 10.1016/j.ejcts.2005.03.013.

4. Neustein SM. The use of bronchial blockers for pr din one-lung ventilation. J Cardiothorac Vasc Anesth ? 9; 860-868, doi: 10.1053/j.jvca.2009.05.014.

5. Cohen E. Pro: the new bronchial blockers ar Anesth 2008; 22: 920-924, doi: 10.1053/j.jvca.200 002.

6. Hillman DR, Platt PR, Eastwood PR. Tr per airway uring anaesthesia. Br J Anaesth 2003; 91: -39, doi-10.1093/bja/ aeg126.

7. Hiremath AS, Hillman DR, James AL, ffcir er WJ, Platt PR, Singer SL. Relationship sen ditticult tracheal intubation and obstructive sleep a oec anaesth 1998; 80: 606-611, doi: $10.1093 / \mathrm{bja} / 80.5$

8. Adams JP, Murphy 5 besity anaesthesia and intensive care. Br J An sth 2 J0; 85: 1-108, doi: 10.1093/bja/ 85.1.91.

9. Loadsman Jf illma. R. Anaesthesia and sleep apnoea. BrJAnaes ר01; 86: _ -266, doi: 10.1093/bja/86.2.254.

10. Lohser $J$, Kulk,$\vee$, Brodsky JB. Anesthesia for thoracic surge in morbidly hese patients. Curr Opin Anaesthesiol 20 2 20: ?-14, dol: 10.1097/ACO.0b013e32800ff73c.

11. C. "ot" Shr"ma S, Shankar R. Obesity, obstructive sleep apno and ibetes mellitus: anaesthetic implications. $\mathrm{Br} \mathrm{J}$ gestr 9; 103 (Suppl 1): i23-i30, doi: 10.1093/bja/ campuo JH. Progress in lung separation. Thorac Surg Clin 05; 15: 71-83, doi: 10.1016/j.thorsurg.2004.09.003.

13. mpos $\mathrm{JH}$, Hallam EA, Ueda $K$. Lung isolation in the morbidly obese patient: a comparison of a left-sided doublelumen tracheal tube with the Arndt ${ }^{\mathbb{R}}$ wire-guided blocker. Br J Anaesth 2012; 109: 630-635, doi: 10.1093/bja/aes206.

14. Li Q, Li P, Xu J, Gu H, Ma Q, Pang L, et al. A novel combination of the Arndt endobronchial blocker and the morbidly obese patients in OLV for thoracic surgery with similar ease of airway establishment as $\mathrm{L}^{-} \mathrm{LL}^{\top}$ better airway pressure, quality lung collapse and si ${ }_{\text {ical }}$ "eld exposure, shorter duration of surgery and esia lower incidence of hoarseness of voice and less in ter and severity of throat pain.

\section{Acknowledgements}

This study is supported by th Sangzh City Science and Technology Research nd ment Projects (No. 151302063).
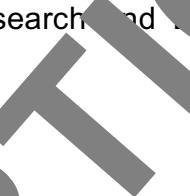

laryngeal $\mathrm{r}$ sk air av ProSeal ${ }^{\mathrm{TM}}$ provides one-lung ventilation for thol _ycry._xp Ther Med 2014; 8: 1628-1632, doi: 10.3892/e

15. Bro Maca. A, Mark JB. Tracheal diameter predicts doub 'um size: a method for selecting left doublelumen s. Anesth Analg 1996; 82: 861-864.

16. Campos $H$, Kernstine $\mathrm{KH}$. A comparison of a left sided Broncho ath with the torque control blocker univent and wire-guided blocker. Anesth Analg 2003; 96: 283-289, 10.1213/00000539-200301000-00056.

mpos $\mathrm{JH}$, Massa CF. Is there a better right-sided tube or one-lung ventilation? A comparison of the right-sided double-lumen tube with the single-lumen tube with rightsided enclosed bronchial blocker. Anesth Analg 1998; 86: 696-700, doi: 10.1213/00000539-199804000-00003.

18. Campos JH, Hallam EA, Van Natta T, Kernstine KH. Devices for lung isolation used by anesthesiologist with limited thoracic experience: comparison of double-lumen endotracheal tube, Univent torque control blocker, and Arndt wireguided endobronchial blocker. Anesthesiology 2006; 104: 261-266, doi: 10.1097/00000542-200602000-00010.

19. Apfelbaum JL, Hagberg CA, Caplan RA, Blitt CD, Connis RT, Nickinovich DG, et al. American Society of Anesthesiologists Task Force on Management of the Difficult Airway. Practice guidelines for management of the difficult airway: an updated report by the American Society of Anesthesiologists Task Force on Management of the Difficult Airway. Anesthesiology 2013; 118: 251-270, doi: 10.1097/ALN. Ob013e31827773b2.

20. Brodsky JB, Lemmens HJ, Brock-Utne JG, Vierra M, Saidman LJ. Morbid obesity and tracheal intubation. Anesth Analg 2002; 94: 732-736, doi: 10.1097/00000539-2002030 00-00047.

21. Seitz PA, Gravenstein N. Endobronchial rupture from endotracheal reintubation with an endotracheal tube guide. J Clin Anesth 1989; 1: 214-217, doi: 10.1016/0952-8180(89) 90044-5.

22. Sener M, Bilen A, Bozdogan N, Kilic D, Arslan G. Laryngeal mask airway insertion with total intravenous anesthesia for transsternal thymectomy in patients with myasthenia gravis: report of 5 cases. J Clin Anesth 2008; 20: 206-209, doi: 10.1016/j.jclinane.2007.07.009.

23. Zavorsky GS, Christou NV, Kim DJ, Carli F, Mayo NE. Preoperative gender differences in pulmonary gas exchange 
in morbidly obese subjects. Obes Surg 2008; 18: 15871598, doi: 10.1007/s11695-008-9527-6.

24. Pelosi P, Luecke T, Rocco PR. Chest wall mechanics and abdominal pressure during general anaesthesia in normal and obese individuals and in acute lung injury. Curr Opin Crit Care 2011; 17: 72-79, doi: 10.1097/MCC.0b013e32 83427213.

25. Salome CM, King GG, Berend N. Physiology of obesity and effects on lung function. J Appl Physiol 2010; 108: 206-211, doi: 10.1152/japplphysiol.00694.2009.

26. Pedoto A. Lung physiology and obesity: anesthetic implications for thoracic procedures. Anesthesiol Res Pract 2012; 2012: ID 154208, doi: 10.1155/2012/154208.

27. Asai T, Howell TK, Koga K, Morris S. Appropriate size and inflation of the laryngeal mask airway. Br J Anaesth 1998; 80: 470-474, doi: 10.1093/bja/80.4.470.

28. Voyagis GS, Batzioulis PG, Secha-Doussaitou PN. Selection of the proper size of laryngeal mask airway in adults. Anesth Analg 1996; 83: 663-664, doi: 10.1213/00000539199609000-00062.

29. Kagawa T, Obara H. An easy formula to remember the laryngeal mask airway size-patient weight relationship. Anesthesiology 2000; 92: 631-632, doi: 10.1097/00000542-2000 02000-00063.

30. Keller C, Brimacombe J, Kleinsasser A, Brimacombe L. The laryngeal mask airway ProSeal ${ }^{\mathrm{TM}}$ as a temporary ventilatory device in grossly and morbidly obese patients before laryn goscope-guided tracheal intubation. Anesth Analg 2002 4: 737-740, doi: 10.1097/00000539-200203000-00048

31. Campos JH. Which device should be considered th st lung isolation: double-lumen endotracheal bronchial blockers. Curr Opin Anaesthesiol 20 doi: 10.1097/ACO.0b013e3280111e2a.

32. Dhonneur G, Ndoko SK, Yavchitz A, Foucrier A, ssenmeyer C, Pollian C, et al. Tracheal cination of mo.oidly obese patients: LMA CTrach vs dit taryng copy. $\mathrm{Br} J$ Anaesth 2006; 97: 742-745, doi: 10 93/bja/s 219.
33. Gonzalez H, Minville V, Delanoue K, Mazerolles M, Concina $D$, Fourcade $O$. The importance of increased nec' ircumference to intubation difficulties in obese patie aresth Analg 2008; 106: 1132-1136, doi: 10.1213/ Ob 3e31 81679659.

34. Neligan PJ, Porter S, Max B, Malhotra G, Greend P, Ochroch EA. Obstructive sleep apne not a risk lactor for difficult intubation in morbidly obest tient Anesth Analg 2009; 109: 1182-1186, do ..1213/a $013 \mathrm{e} 318$ $1 \mathrm{~b} 12 \mathrm{a} 0 \mathrm{c}$.

35. Riad W, Vaez MN, Raveendrar Tam , Quereshy FA, Chung $F$, et al. Neck circur enc dictor of difficult intubation and difficult ask tilation in morbidly obese patients: a prospecti observa al study. Eur J Anaesthesiol 2016; 33 24. 49, doi: 10.1097/EJA.0000000 000000324.

36. Campos JH. ac on lung separation techniques: doublelumen tube and anchial blockers. Rev Mex Anest 2011; 34 (Supl 1).

37. Knoll H, Ziege, S, Schreiber JU, Buchinger H, Bialas P, Sen $\quad K$ et a. irway Injuries after one-lung ventilation: a col aris ween double-lumen tube and endobronchial h er: a randomized, prospective, controlled trial. Anesthe logy 2006; 105: 471-477, doi: 10.1097/0000 0542-200,09000-00009.

38. hmann M, Monte K, Barach P, Kindler CH. Postoperative p ent complaints: a prospective interview study of 12,276 cents. J Clin Anesth 2010; 22: 13-21, doi: 10.1016/ gclinane.2009.02.015.

29. Goldmann K, Dieterich J, Roessler M. Laryngopharyngeal mucosal injury after prolonged use of the ProSeal LMA in a porcine model: a pilot study. Can $J$ Anaesth 2007; 54: 822-828, doi: 10.1007/BF03021710.

40. Li P, Liang $W, G u H$. One-lung ventilation using Proseal ${ }^{\mathrm{TM}}$ laryngeal mask airway and Arndt endobronchial blocker in paediatric scoliosis surgery. $\mathrm{Br} J$ Anaesth 2009; 103: 902-903, doi: 10.1093/bja/aep325. 